\title{
Public Access Technologies in Public Libraries: Effects and Implications
}

Public libraries were early adopters of Internet-based technologies and have provided public access to the Internet and computers since the early 1990s. The landscape of public-access Internet and computing was substantially different in the 1990s as the World Wide Web was only in its initial development. At that time, public libraries essentially experimented with publicaccess Internet and computer services, largely absorbing this service into existing service and resource provision without substantial consideration of the management, facilities, staffing, and other implications of public-access technology (PAT) services and resources. This article explores the implications for public libraries of the provision of PAT and seeks to look further to review issues and practices associated with PAT provision resources. While much research focuses on the amount of public access that public libraries provide, little offers a view of the effect of public access on libraries. This article provides insights into some of the costs, issues, and challenges associated with public access and concludes with recommendations that require continued exploration.

$\mathbf{P}$ ublic libraries were early adopters of Internet-based technologies and have provided public access to the Internet and computers since the early 1990s. ${ }^{1}$ In 1994, 20.9 percent of public libraries were connected to the Internet, and 12.7 percent offered public-access computers. By 1998, Internet connectivity in public libraries grew to 83.6 percent, and 73.3 percent of public libraries provided public Internet access. ${ }^{2}$ The landscape of public-access Internet and computing was substantially different in the 1990s, as the World Wide Web was only in its initial development. At that time, public libraries essentially experimented with public-access Internet and computer services, largely absorbing this service into existing service and resource provision without substantial consideration of the management, facilities, staffing, and other implications of public-access technology (PAT) services and resources. ${ }^{3}$

Using case studies conducted at thirty-five public libraries in five geographically dispersed and demographically diverse states, this article explores the implications

John Carlo Bertot (jbertot@umd.edu) is Professor and Director of the Center for Library Innovation in the College of Information Studies at the University of Maryland, College Park. for public libraries of the provision of PAT. The researcher also conducted interviews with state library agency staff prior to visiting libraries in each state. The goals of this article are to

- explore the level of support PAT requires within public libraries;

- explore the implications of PAT on public libraries, including management, building planning, staffing, and other support issues;

- explore current PAT support practices;

- identify issues and challenges public libraries face in maintaining and supporting their PAT infrastructure; and

- identify factors that contribute to successful PAT practices.

This article seeks to look beyond the provision of PAT by public libraries and review issues and practices associated with PAT-provision resources. While much research focuses on the amount of public access that public libraries provide, little offers a view of the effect of public access on libraries. This article provides insights into some of the costs, issues, and challenges associated with public access, and it concludes with recommendations that require continued exploration.

\section{Literature review}

Quickly over time, public libraries increased their public-access provision substantially (see figures 1 and 2). Connectivity grew from 20.9 percent in 1994 to nearly 100 percent in $2006 .{ }^{4}$ Moreover, nearly all libraries that connected to the Internet offered public-access Internet services. Simultaneously, the average number of publicaccess computers grew from 1.9 per public library in 1996 to 12 per public library in 2007.5 Accompanying and in support of the continual growth of basic connectivity and computing infrastructure was a demand for broadband connectivity. Indeed, since 1994, connectivity has progressed from dial-up phone lines to leased lines and other forms of high-speed connectivity. The extent of the growth in public-access services within public libraries is profound and substantive, leading to the development of new Internet-based service roles for public libraries. ${ }^{6}$ And public access to the Internet through public libraries provides a number of community benefits to different populations within served communities. ${ }^{7}$

Overlaid onto the public-access infrastructure is an increasingly complex service mix that now includes access to digital content (e.g., databases and digital 


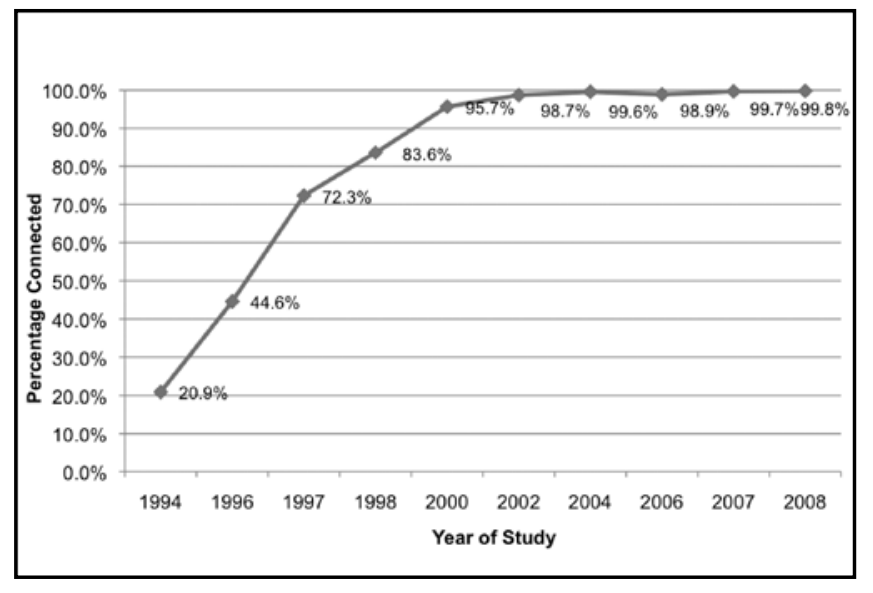

Figure 1. Public-access Internet connectivity from 1994 through 2008

libraries), integrated library systems (ILSs), Voice over Internet Protocol (VoIP), digital reference, and a host of other services and resources-some for public access, others for back-office library operations. And patrons do use these services in increasing amounts-both in the library and in everyday life. ${ }^{8}$ In fact, 82.5 percent of public libraries report that they do not have an adequate number of public-access computers some or all of the time and have resorted to time limits and wireless access to extend public-access services. ${ }^{9}$

By 2007, as connectivity and public-access computer infrastructure grew, so ensued the need to provide a range of publicly available services and resources:

- 87.7 percent of public libraries provide access to licensed databases

- 83.4 percent of public libraries offer technology training

- 74.1 percent of public libraries provide e-government services (e.g., locating government information and helping patrons complete online applications)

- 62.5 percent of public libraries provide digital reference services

- 51.8 percent of public libraries offer access to e-books ${ }^{10}$

The list is not exhaustive, but illustrative, since libraries do offer other services such access to homework resources, video content, audio content, and digitized collections.

As public libraries expanded these services, management realized that they needed to plan and evaluate technology-based services. Over the years, a range

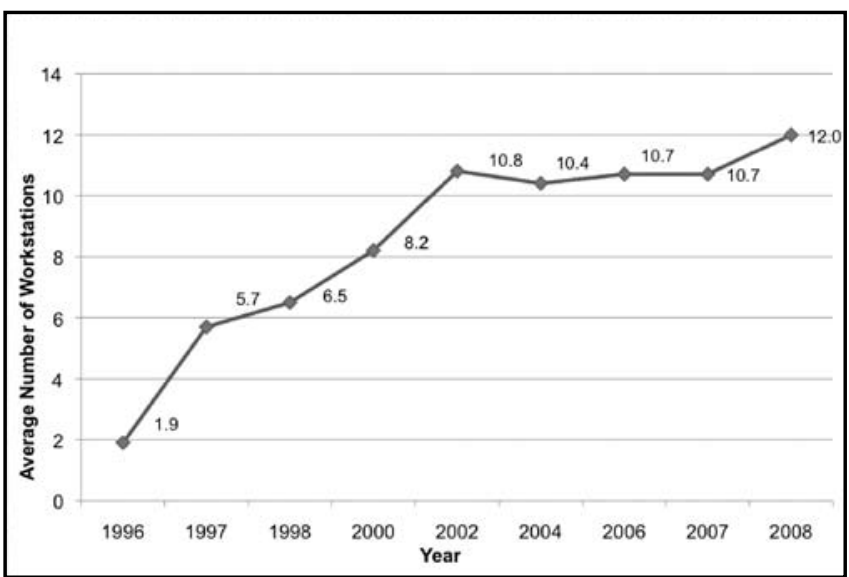

Figure 2. Public-access Internet workstations from 1996 through 2008

of technology management, planning, and evaluation resources emerged to help public libraries cope with their technology-based resources-those both publicly available and for administrative operations. ${ }^{11}$

But increasingly, public libraries report the strain that PAT services promulgate. This centers on four key areas:

- Maintenance and Management. The necessary maintenance and management requirements of PAT places an additional burden on existing staff, many of whom do not possess technology expertise to troubleshoot, fix, and support Internet-based services and resources that patrons access.

- Staff. Libraries consistently cite staff expertise and availability as a barrier to the addition, support, and management of PAT. Indeed, as described in previous sections, some libraries have experienced a decline in library staff.

- Finances. There is evidence of stagnant funding for libraries at the local level as well as a shift in expenditures from staff and collections to operational costs such as utilities and maintenance.

- Buildings. The buildings are inadequate in terms of space and infrastructure (e.g., wiring and cabling) to support additional public access. ${ }^{12}$

This article explores these four areas through a sitevisit method in an effort to go beyond a quantitative assessment of PAT within the public library community. Though related in terms of topic area and author, this study was conducted separately from the Public Library Internet surveys conducted since 1994 and offers insights into the provision of PAT services and resources that a national survey cannot explore in such depth. 


\section{Method}

The researcher visited thirty-five public libraries in five geographically and demographically diverse states between October 2007 and May 2008. The states were in the West, Southwest, Southeast, and Mid-Atlantic regions. The libraries visited included urban, suburban, rural, and Native American public libraries that served populations ranging from a few hundred to more than half a million. The communities that the libraries served varied in terms of poverty, race, income, age, employment, and education demographics. Prior to visiting the public library sites, the researcher conducted interviews with state library agency staff to better understand the public library context within each state and to explore overall PAT issues, strategies, and other factors within the state.

The following research questions guided the site visits:

- What are the community and library contexts in which the library provides PAT?

- What are the PAT services and resources that the library makes available to its community?

- What PAT services and resources does the library desire to provide to its community?

- What is the relationship between provided and desired PAT and the effect on the library (e.g., staff, finances, the building, and management)?

- What are the perceived benefits to the library and its community gains through PAT in the library?

- What are the issues and barriers that the library encounters in providing PAT services and resources?

- How does the library manage and maintain its PAT?

The researcher visited each library for four to six hours. During that time, he interviewed the library director and/or branch manager and technology support staff (either a specific library position, designated library employee, or city or county IT staff person), toured the library facility, and conducted a brief technology inventory. At some libraries, the researcher was able to meet with community partners that in some way collaborated with the library to provide PAT services and resources (e.g., educational institutions that collaborated with libraries to provide access to broadband or volunteers who conducted technology training sessions).

Interviews were recorded and transcribed, and the technology inventories were entered into a Microsoft Excel spreadsheet for analysis. The transcripts were coded using thematic content analytic schemes to allow for the identification of key issues regarding PAT areas. ${ }^{13}$ This approach enabled the researcher to use an iterative site-visit strategy that used findings from previous site visits to inform subsequent visits.

To ensure valid and reliable data, the researcher used a three-stage strategy:

1. Site-visit reports were completed and sent to th libraries for review. Corrections from libraries were incorporated into a final site-visit report.

2. A final state-based site-visit report was compiled for distribution to state library agency staff and also incorporated their corrections. This provided a state-level reliability and validity check.

3. A summary of key findings was distributed to six experts in the public library technology environment, three of which were public library technology managers and three of which were technology consultants who worked with public libraries.

In combination, this approach provided three levels of data quality checks, thus providing both internal (library and state) and external (technology expert) support for the findings.

The findings in this article are limited to the libraries visited and interviews conducted with public librarians and state library agency staff. However, themes emerged early during the site-visit process and were reinforced through subsequent interviews and visits across the states and libraries visited. In addition, the use of external reviewers of the findings lends additional, but limited, support to the findings.

\section{Findings}

This section presents the results of the site visits and interviews with state library agency staff and public librarians. The article presents the findings by key areas surrounding PAT in public libraries.

\section{The public-access context}

Public libraries have a range of PAT installed in their libraries for patron use. These technologies include public-access computers, wireless (WiFi) access, ILSs, online databases, digital reference, downloadable audio and video, and others. Many of these services and resources are also available to patrons from outside library buildings, thus extending the reach (and support issues) of the library beyond the library's walls. In addition, when libraries do not provide direct access to resources and services, they serve as access points to those services, such as online gaming and social networking.

While libraries can and do deploy a number of technologies for public use, it is possible to group these 
technologies broadly into two overlapping categories:

- Hardware. Library PAT hardware can include public-access computers, public-access computing registration (i.e., reservation) systems, self-checkout stations, printers, faxes, laptops, and a range of other devices and systems. Some of these technologies may have additional devices, such as those required for persons with disabilities. Within the hardware grouping are networking technologies that include a range of hardware and software to enable a range of library networks to run (e.g., routers, hubs, switches, telecommunications lines, and networking software).

- Software. Software can include device operating system software (e.g., Microsoft Windows, Mac OS, and Linux), device application software (e.g., Microsoft Office, OpenOffice, graphics software, audio software, e-book readers, assistive software, and others), and functional software (e.g., Web browsers, online databases, and digital reference).

In short, public libraries make use of a range of technologies that the public uses in some way. Each type of technology requires skills, management, implementation, and maintenance, all of which are discussed later.

In the building, all of these products and services come together at the library's public-access computers, or patron mobile device if WiFi is available. Moreover, patrons increasingly want to use their portable devices (e.g., USB drives, iPods, and others) with library technology. This places pressure on libraries to not just offer public-access computers, but also to support a range of technologies and services.

Thus the environment in which libraries offer PAT is complex and requires substantial technical expertise, support, and maintenance in key areas of applications, computers, and networking. Moreover, as discussed below, patrons are increasingly demanding market-based approaches to PAT. These demands-which are largely about single-point access to a range of information services and resources-are often at odds with library technology that is based on stove-piped approaches (e.g, ILS, e-books, and licensed resources) and that do not necessarily lend themselves to seamless integration.

\section{External pressures on PATs}

The advent and increased use by the public of Google, Amazon, iTunes, YouTube, MySpace, Second Life, and other networked services affects public libraries in a number of ways. This article discusses these services and resources from the perspective of an information marketplace of which the public library is one entrant.

Interviewed librarians overwhelmingly indicated that users now expect library services to resemble those in the marketplace. Users expect the look and feel, integration, service capabilities, interactivity, and personalization and customization that they experience while engaging in social networking, online searching, online purchasing, or other online activities. And within the library building, patrons expect the services to integrate at the public-access computer entry point-not distributed throughout the library in a range of locations, workstations, or devices. Said differently, they expect to have a "MyLibrary.com" experience that allows for seamless integration across the library's services but also facilitates the use of personal technologies (e.g., iPods, MP3 players, and USB devices). Thus users expect the library's services to resemble those services offered by a range of information service providers.

Importantly, however, librarians indicated that library systems on which their services and resources reside by and large do not integrate seamlessly-nor were they designed to do so. Public-access computers are gateways to the Internet; the ILS exists for patrons to search for and locate library holdings; and online databases, e-books, audiobooks, etc., are extensions of the library's holdings but are not physical items under a library's control and thus subject to a vendor's information and business models. While library vendors and the library community are working to develop more integrated products that lead users to the information they seek, the technology is under development.

There are three significant issues that libraries face because of market pressures: (1) The pressures all come together at a single point-the public-access computer; (2) users want a customized experience while using technology designed for the general public, not the individual user; and (3) users have choices in the information marketplace. One participant indicated, "If the library cannot match what users have access to on the outside, users will and do move on."

\section{Managing and maintaining public access}

Managing the public-access computer environment for public libraries is an growing challenge. There are a number of management areas with which public librarians contend:

- Public-access computers - the computers and laptops (if applicable) themselves, which can include anything from keyboards and mice to troubleshooting a host of computer problems (it is important to note that these may be computers that often vary in age and composition, come from a range of vendors, run different operating systems, and often 
have different application software versions).

- Peripheral management-the printers, faxes, scanners, and other equipment that are part of the library's overall public access infrastructure.

- Public-access management software or systems-these may include online or in-building computer-based reservations (which encompasses specialized reservations such as teen machines, gaming computers, computers for seniors, and so on), time management (set to the library's decided-upon time allotment), filtering, security, logins, virtual machines, etc.

- Wireless access - this may include logins and configurations for patrons to gain access to the library's wireless network.

- Bandwidth management-this may include the need to allocate bandwidth differently as needs increase and decrease in a typical day.

- Training and patron assistance-for a vast array of services such as databases, online searching, e-government (e.g., completing government forms and seeking government information), and others. Training can take place formally through classes, but also through point-of-use tutorials requested by patrons.

To some extent, librarians commented that, while they do have issues with the public-access computers themselves from time to time, the real challenges that they face regard the actual management of the publicaccess environment-sign-ups, time limits, cost recovery for print jobs, helping patrons, and so on. One librarian commented that "the computers themselves are pretty stable. We don't really have too many issues with them per se. It's everything that goes into, out from, or around the computer that creates issues for us."

As a result of the management challenges, severallibraries have adopted turn-key solutions, such as public-access management systems (e.g., Comprise Technology's Smart Access Manager [http://www.comprisetechnologies .com/product_29.html]) and all-encompassing public computing management systems that include networking and desktops (e.g., Userful's DiscoverStations [http:// userful.com/libraries/]). These systems allow for an allin-one sign-up, print cost recovery, filtering (if desired), and security approach. Also, the DiscoverStations are a Linux-based, all encompassing public-access management environment. A clear advantage to the DiscoverStation approach is that the DiscoverStation is connected to the Internet and is accessible by Userful staff remotely to update software and perform other maintenance functions. They also use open-source operating and application software.

While these solutions do provide efficiencies, they also can create limitations. For example, the DiscoverStations are a thin-client system and are dependent on the server for graphics and memory, thus limiting their ability to access gaming and social-networking sites. The Smart Access Manager, and similar programs, can rely on smart cards or other technology that users must purchase to print. Another limitation is that the time limits are fixed, and, while users get warnings as time runs out, the session can end abruptly.

These approaches are by and large adopted by libraries to ease the management associated with public-access computers and let staff concentrate on other duties and responsibilities. One librarian indicated that "until we had our management system, we would spend most of the day signing people up for the computers, or asking them to finish their work for the next person in line."

\section{Planning for PAT services and resources}

Public libraries face a number of challenges when planning for PAT services and resources. This is primarily because PAT planning involves more than computers. Any planning needs to encompass

- building needs, requirements, limitations, and design;

- technology assessment that considers the library's existing technology, technology potential, current practices, and future trends;

- planning for and supporting multiple technology platforms;

- telecommunications and networking;

- services and resources available in the marketplace-those specifically for libraries and those more broadly available to consumers and used by patrons;

- specific needs and requirements of technology (e.g., memory, disk space, training, other);

- requirements of other IT groups with which the library may need to integrate, for example, city or county technology mandates;

- support needs, including the need to enter into maintenance agreements for computer, network, and other equipment and software;

- staff capabilities, such as current staff skill sets and their ability to handle the technologies under review or purchased; and

- policy, such as requirements to filter because of local, state or federal mandates.

The above list may not be exhaustive, but rather based on the main items that librarians identified during the site visits, and they serve to provide indicators of the challenges those planning library IT initiatives face. 


\section{The endless upgrade and planning}

One librarian likened the PAT environment to "being a gerbil on a treadmill. You go round and round and never really arrive," a reference to the fact that public libraries are in a perpetual cycle of planning and implementing various PAT services and resources. Either hardware needs to be updated or replaced, or there is a software update that needs to be installed, or libraries are looking to the next technology coming down the road. In short, the technology planning to implementation cycle is perpetual.

The upgrade and replacement cycle is further exacerbated by the funding situation in which most public libraries find themselves. Increasingly, public library local and state funding, which combined can account for more than 90 percent of library funding, is flat or declining. ${ }^{14}$ The most recent series of Public Library Internet studies indicates an increase in reliance by public libraries on fees and fines, fundraising, private foundation, and grant funding to finance collections and technology within libraries. ${ }^{15}$ This places key aspects of library operations in the realm of unreliable and one-time funding sources, thus making it difficult for libraries to develop multiyear plans for PAT.

\section{Multiple support models}

To cope with PAT management and maintenance issues, public libraries are developing various support strategies. The site visits found a number of technology-support approaches in effect, ranging from no IT support to highly centralized statewide approaches. The following list describes the technology-support models encountered during the site visits:

1. No technology support. Libraries in this group have neither technology-support staff nor any type of organized technology-support mechanism with existing library staff. Nor do they have access to external support providers such as county or city IT staff. Libraries in this group might rely on volunteers or engage in ad hoc maintenance, but by and large have no formal approach to supporting or maintaining their technology.

2. Internal library support without technology staff. In this model, the library provides its own technology support but does not necessarily have dedicated technology staff. Rather, the library has designated one or more staff members to serve as the IT person. Usually this person has an interest in technology but has other primary responsibilities within the library. There may be some structure to the support-such as updating software (e.g., Windows patches) once a week at a certain timebut it may be more ad hoc in approach. Also, the library may try to provide its designated IT person(s) with training to develop his or her skills further over time.

3. Internal library support with technology staff. In this model, the library has at least one dedicated IT staff person (part- or full-time) who is responsible for maintaining and planning the library's PAT environment. The person may also have responsibilities for network maintenance and a range of technology-based services and resources. At the higher end of this approach are libraries with multiple IT staff with differing responsibilities, such as networking, telecommunications, public-access computers, the ILS, etc. Libraries at this end of the spectrum tend to have a high degree of technology sophistication but may face other challenges (i.e., staffing shortages in key areas).

4. Library consortia. Over the years, public libraries have developed consortia for a range of servicesshared ILSs, resource sharing, resource licensing, and more. As public-library needs evolve, so too do the roles of library consortia. Consortia increasingly provide training and technology-support services, and may be funded through membership fees, state aid, or other sources.

5. Technology partners. While some libraries may rely on consortia for their technology support, others are seeking libraries that have more technology expertise, infrastructure, and abilities with whom to partner. This can be a fee-for-service arrangement that may involve sharing an ILS, a maintenance agreement for network and public-access computer support, and a range of services. These arrangements allow the partner libraries to have some input into the technology planning and implementation processes without incurring the full expense of testing the technologies, having to implement them first, or hiring necessary staff (e.g., to manage the ILS). The disadvantage to this model is that the smaller partner libraries are dependent on the technology decisions that the primary partner makes, including upgrade cycles, technology choices, migration time frames, etc.

6. City, county, or other agency IT support. As city or county government agencies, some libraries receive technology support from the city or county IT department (or in some cases the education department). This support ranges from a full slate of services and support available to the library to support only for the staff network and computers. 
Even at the higher end of the support spectrum, librarians gave mixed reviews for the support received from IT agencies. This was primarily because of competing philosophies regarding the PAT environment, with public librarians wanting an open-access policy to allow users access to a range of information service and resources and IT agency staff wanting to essentially lock down the public-access environment and thus severely limit the functionality of the public-access computers and network services (i.e., wireless). Other limitations might include prescribed PAT, specified vendors, and bidding requirements.

7. State library support. One state library visited provides a high degree of service through its statewide approach to supporting public-access computing in the state's public libraries. The state library has IT staff in five locations throughout the state to provide support on a regional level but also has additional staff in the capital. These staff offer training, inhouse technical support, phone support, and can remote access the public-access computers in public libraries to troubleshoot, update, and perform other functions. Moreover, this state built a statewide network through a statewide application to the federal E-Rate program, thus providing broadband to all libraries. This model extends the availability of qualified technical support staff to all public libraries in the state- by phone as well as in person if need be. As a result, this enables public libraries to concentrate on service delivery to patrons.

It is important to note that there are combinations of the above models in public libraries. For example, some libraries support their public-access networks and technology while the county or city IT department supports the staff network and technology. It is clear, however, that there are a number of models for technology support in public libraries, and likely more than are presented in this article. The key issue is that public libraries are engaging in a broad spectrum of strategies to support, maintain, and manage their PAT infrastructure.

Also of significance is that there are public libraries that have no technology-support services that provide PAT services and resources. These libraries tend to serve populations of less than ten thousand, are rural, have fewer than five full-time equivalents (FTEs), and are unlikely to be staffed by professional librarians.

\section{Staff needs and pressures}

The study found a number of issues related to the effect of PAT on library staff. This section of the findings discusses the primary factors affecting library staff as they work in the public-access context.

\section{Multiple skills needed}

Not only is the pace of technological change increasing, but the change requires an ever-increasing array of skills because of the complexity of applications, technologies, and services. An example of such complexity is the library OPAC or ILS. Visited libraries indicated that such systems are becoming so complex and technologically sophisticated that there is a need for a full-time staff person to run and maintain the library ILS.

Given the range of hardware, software, and networking infrastructure, as well as planning and PAT management requirements, public librarians need a number of skills to successfully implement and maintain their PAT environments. Moreover, the skill needs depend on the librarian's position-for example, an actual IT staff person versus a reference librarian who does double duty by serving as the library's IT person. The skills required fall into technology, information literacy, service and facilities planning, management, and leadership and advocacy areas:

- Technology

- General computer troubleshooting

- Basic maintenance, such as mouse and keyboard cleaning

- Basic computer repair, such as memory replacement, floppy drive replacement, disk defragmentation, etc.

- Basic networking, such as troubleshooting an "Internet" issue versus a computer problem

- Telecommunications so as to understand the design and maintenance of broadband networks

- Integrated library systems

- Web design

- Information literacy

- Searching and using Internet-based resources

- Searching and using library licensed resources

- Training patrons on the use of the publicaccess computers, general Internet resources, and library resources

- Designing curriculum for various patron training courses

- Services and facilities planning

- Technology plan development and implementation (including budgeting)

- Telecommunications planning (including 
E-Rate plan and application development)

- Building design so as to accommodate the requirements of public access technologies

- Management

- License and contract negotiation for licensed resources, various public-access software and licenses, and maintenance agreements (service and repair agreements)

- Integration of PAT into library operations

- Troubleshooting guidelines and process

- Policy development, such as acceptable use, filtering, filtering removal requests by patrons, etc.

- Leadership and advocacy

- Grant writing and partnership development so as to fund PAT services and resources and extend out into the community that the library serves

- Advocacy so as to be able to demonstrate the value of PAT in the library as a community good

- Leadership so as to build a community approach to public access with the library as one of the foundational institutions

These items provide a broad cross section of the skills that public library staff may need to offer a robust PAT environment. In the case of smaller, rural libraries, these requirements in general fall to the library director-along with all other duties of running the public library. In libraries that have separate technology, collections development, and other specialized staff, the skills and expertise may be dispersed throughout various areas in the library.

\section{Training}

Public librarians receive a range of technology trainingincluding none at all. In some cases, this might be a basic workshop on some aspect of technology at a state library association annual meeting or a regional workshop hosted by the library's consortium. It could be an online course through WebJunction (http://www.webjunction .org/). It could be a one-on-one session with a vendor representative or colleague. Or it could be a formal, multiday class regarding the latest release of an ILS. If available, public librarians have access to technology training that can take many forms, has a wide array of content (basic to expert), and can enhance staff knowledge about IT with varying degrees of success.

An issue raised by librarians was that having access to training and being able to take advantage of training are two separate things. Regardless of the training delivery medium, librarians indicated that they were not always able to get release time to attend a training session. This was particularly the case for small, rural libraries that had less than five FTEs spread out over several part-time individuals. For these staff to take advantage of training would require a substitute to cover public-service hours-or shut down the library.

\section{Funding information technology}

As one might expect, there was a range of technology budgets in the public libraries visited or interviewedfrom no technology budget to a substantial technology budget, and many points in between. Some libraries had a dedicated IT budget line item, others had only an operating budget out of which they might carve some funds for technology. Libraries with dedicated IT budgets by and large had at least one IT staff person; libraries with no IT budget largely relied on a staff person responsible for other library functions to manage their technology. In the smallest libraries, the library director served as the technology specialist in addition to being the general library operation manager.

Some libraries have established foundations through which they can raise funds for technology, among other library needs. Many seek grants and thus devote substantial effort to seeking grant initiatives and writing grant proposals. Some libraries held fundraisers and worked with their Library Friends groups to generate funds. Other libraries engage in all of the above efforts to provide for their PAT infrastructure, services, and resources. In short, there are several budgetary approaches public libraries use to support their PAT environment. Critical to note is that a number of libraries are increasingly relying on nonrecurring funds to support PATs, a fact corroborated by the 2007 and 2008 Public Library Internet surveys. ${ }^{16}$

\section{The buildings}

When one visits public libraries, one is immediately struck by the diversity in design, functionality, and architecture of the buildings. Public libraries often reflect the communities that they serve not only in the collection and service, but also in the facilities. This diversity serves the public library community well because it allows for a custom approach to libraries and their community.

The building design, however, can also be a source of substantial challenge for public libraries. The increased integration of technology into library service places a range of stresses on buildings-physical space for workstations and other equipment and specialized furniture, power, server rooms, and cabling, for example. Along with the library-based technology requirements come those of patrons-particularly the need for power so that 
patrons may plug in their laptops or other devices. Also important to note is that the building limitations also extend to staff and their access to computing and networked technologies.

A number of librarians commented that they are "simply at capacity." One librarian summed it up by stating that "there's no more room at the inn. Unless we start removing parts of our collection, we don't have any more room for workstations." Another said that, "while we do have the space to add more computers, we don't have enough power or outlets to support them. And, with our building, it's not a simple thing to add." In short, many libraries are reaching, or have reached, a saturation point as to just how much PAT they can support.

\section{Discussion and implications}

Over time, PAT services have become essential services that public libraries provide their communities. With nearly all public libraries connected to the Internet and offering public-access computers, the high percentage of libraries that offer Internet-based services and resources, the overall usage of these resources by the public, ${ }^{17}$ and 73 percent of public libraries reporting that they are the only free provider of PAT in their communities, it is clear that the provision of PAT services is a key and critical service role that public libraries offer. ${ }^{18}$ It is also clear, however, that the extent to which public libraries can continue to absorb, update, and expand their PAT depends on the resolution of a number of staffing, financial, maintenance and management, and building barriers.

In a time of constrained budgets, it is unlikely that libraries will receive increased operational funding. Indeed, reports of library funding cuts are increasing in the current economic downturn, which affects the ability of libraries to increase, or significantly update, staff-particularly in the areas of technology, licensing additional resources, procuring additional and new computers, and purchasing and offering expanded services such as digital photography, gaming, or social networking. ${ }^{19}$ Moreover, the same financial constraints can affect the ability of libraries to raise capital funds for building improvements and new construction.

Funding also has an effect on the training that public libraries can offer or develop for their staff. And training is becoming increasingly important to the success of PAT services and resources in public libraries-but not just training regarding the latest technologies. Rather, there is a need for training that provides instruction on the relationship between the level of PAT services and resources a library can or desires to provide and advocacy; broadband, computing, and other needs; technology planning and management; collaboration and partnering; and leadership. The public library PAT environment is complex, encompasses a number of technologies, and has ties to many community services and resources. Training programs need to reflect this complexity.

The continued provision of PAT services in public libraries is increasingly burdensome on the public library community, and the pressures to expand their PAT services and resources continues to grow-particularly as libraries report their "sole provider" of free PAT status in their communities. The successful libraries in terms of PAT services and resources visited had staff that could

- understand PAT (both in terms of functionality and potential);

- think creatively across the technology and library service spectrum;

- integrate online content, PAT, and library services;

- articulate the value of PAT as an essential community need and public library service;

- articulate the role of the perception of the library by its community as a critical bridge to online content;

- demonstrate leadership within the community and library;

- form partnerships and extend PAT services and resources into the community; and

- raise funds and develop other support mechanisms to enhance PAT services and resources in the library and throughout the community.

In short, successful PAT in libraries was being redefined in the context of communitywide PAT service and resource provision. This approach not only can lead to a more robust community PAT infrastructure, but it also lessens the library's burden of PAT service and resource provision.

But equally important to note is that the extent to which all public libraries can engage in these activities on their own is unclear. Indeed, several libraries visited were struggling to maintain basic PAT service levels and indicated that increasing PAT services came at the expense of other library services. "We're trying to meet demand," one librarian said, "but we have too few computers, too slow a connection, and staff don't always know what to do when things go wrong or someone comes in talking about the latest technology or website." For some libraries, therefore, quality PAT services that meet community needs are simply out of reach.

Thus another implication and finding of the study is the need for libraries to explore other models of support for their PAT environments-for example, using the services of a regional cooperative, if available; if none is available, libraries could form their own cooperative for resource sharing, technology support, and other aspects of PAT service provision. The same approach could be 
taken within a city or county to enhance technology support throughout a region. Another approach would be to outsource a library's PAT support and maintenance to a nearby library with support staff in a fee-for-service approach. There are a number of approaches that libraries could take to support their PAT infrastructure. A key point is that libraries need to consider PAT service provision in a broader community, regional, or state context, and the study found some libraries doing so.

The need to avail staff of the skills required to truly support PAT was a recurring theme throughout the site visits. Approaches and access to training varied. For example, some state libraries provided-either directly or through the hiring of consultants and instructors-a number of technology-related courses taught in regional locations. An example of this approach is California's InfoPeople project (http://www.infopeople .org/). Some state libraries subscribed to WebJunction (http://www.webjunction.org/), which provides access to online instructional content. Online manuals provided by CompuMentor through a grant funded by the Bill and Melinda Gates Foundation aimed at helping rural libraries support their PAT (www.maintainitproject.org) are another resource. Beyond technology skills training, however, is the need for technology planning, effective communication, leadership, value demonstration, and advocacy. The extent to which leadership, advocacy, and library marketing, for example, are able to be taught remains a question.

All of these issues take place with the backdrop of an economic downturn and budgetary constraints. Increased operating costs created through inflation and higher energy costs place substantial pressures on public libraries simply to maintain current levels of servicemuch less engage in the additional levels of service that the PAT environment brings. Indeed, as the 2008 Public Library Funding and Technology Access Study demonstrated, public libraries are increasingly funding their technology-based services through non-recurring funds such as fines and fundraising activities. ${ }^{20}$ Thus, the ability of public libraries to provide robust PAT services and resources is increasingly limited unless such service provision comes at the expense of other library services. Alone, the financial pressures place a high burden on public libraries. Combined with the building, staffing, skills, and other constraints reported by public libraries, however, the emerging picture for library PAT services and resources is one of significant challenge.

\section{Three key areas for additional exploration}

The findings from the study point to the need for additional research and exploration of three key services areas and issues related to PAT support and services:

1. Develop a better understanding of success in the PAT environment. This study and the 2006 study by Bertot et al. point to what is required for libraries to be successful in a networked environment. ${ }^{21} \mathrm{In} \mathrm{fact,}$ the 2007 Public Libraries and the Internet report contained a section entitled "The Successfully Networked Public Library," which offered a range of checklists for public libraries (and others) to consider as they planned and implemented their networked services. ${ }^{22}$ This study identified additional success factors and considerations focused specifically on the public access technology environment. Together, these efforts point to the need to better understand and articulate the critical success factors necessary for public libraries to plan, implement, and update their PAT given current service contexts. This is particularly necessary in the context of meeting user expectations and needs regarding networked technologies and services.

2. Further identify technology-support models. This study uncovered a number of different technologysupport models implemented by public libraries. Undoubtedly there are additional models that require identification. But, more importantly, there is a need to further explore how each technologysupport model assists libraries, under what circumstances, and in what ways. Some models may be more or less appropriate on the basis of the service context of the library-and that is not clearly understood at this time.

3. Levels of service capabilities. An underlying theme throughout this research, and one that is increasingly supported by the Public Library and the Internet studies, is that the PAT service context is essentially a continuum from low service and capability to high service and capability. There are a number of factors contributing to where libraries may lie on the success continuum-funding, management, leadership, attitude, skills, community support, and innovation, to name a few. This continuum requires additional research, and the research implications could be profound. Emerging data indicate that there are public libraries that will be unable to continue to evolve and meet the increased demands of the networked environment, both in terms of staff and infrastructure. Public libraries will have to make choices regarding the provision of PAT services and resources in light of their ability to provide high-quality services (as defined by their service communities). For better or worse, the technology environment continually evolves and requires new technologies, management, and support. That is, 
and will continue to be, the nature of public access to the Internet.

Though there are likely other issues worthy of exploration, these three are critical to further our understanding of the PAT environment and public library roles and issues associated with the provision of public access.

\section{Conclusion}

The PAT environment in which public libraries operate is increasingly complex and continues to grow in funding, maintenance and management, staffing, and building demands. Public libraries have navigated this environment successfully for more than fifteen years; however, stresses are now evident. Libraries rose quickly to the challenge of providing public-access services to the communities that they serve. The challenges libraries face are not necessarily insurmountable, and there are a range of tools designed to help public libraries plan and manage their public-access services. These tools, however, place the burden of public access, or assume that the burden of public access in placed, on the public library. Given increased operating costs because of inflation, the continual need to innovate and upgrade technologies, staff technology skills requirements, and other factors discussed in this article, libraries may not be in a position to shoulder the burden of public access alone. Thus there is a need to reconsider the extent to which PAT provision is the sole responsibility of the library; perhaps there is a need to integrate and expand public access throughout a community. The potential of such an approach can benefit a community through an integrated and broader access strategy, but also can relieve the pressure on the public library as the sole provider of public access.

\section{Acknowledgement}

This reserach was made possible in part through the support of the MaintianIT Project (http://www.maintainit project.org/), an effort of the nonprofit TechSoup Web resource (http:/ / www.techsoup.org/).

\section{References}

1. Charles R. McClure, John Carlo Bertot, and Douglas L. Zweizig, Public Libraries and the Internet: Study Results, Policy Issues, and Recommendations (Washington, D.C.: National
Commission on Libraries and Information Science, 1994).

2. John Carlo Bertot and Charles R. McClure, Moving Toward More Effective Public Internet Access: The 1998 National Survey of Public Library Outlet Internet Connectivity (Washington, D.C.: National Commission on Libraries and Information Science, 1998), http:/ / www.liicenter.org/Reports /1998_plinternet_ study.pdf (accessed Apr. 22, 2009).

3. Charles R. McClure, John Carlo Bertot, and John C. Beachboard, Internet Costs and Cost Models for Public Libraries (Washington, D.C.: National Commission on Libraries and Information Science, 1995).

4. Charles R. McClure, John Carlo Bertot, and Douglas L. Zweizig, Public Libraries and the Internet: Study Results, Policy Issues, and Recommendations (Washington, D.C.: National Commission on Libraries and Information Science, 1994); John Carlo Bertot, Charles R. McClure, Paul T. Jaeger, and Joe Ryan, Public Libraries and the Internet 2006: Study Results and Findings (Tallahassee, Fla.: Information Institute, 2006), http://www .ii.fsu.edu/projectFiles/plinternet/2006/2006_plinternet.pdf (accessed Mar. 5, 2009).

5. John Carlo Bertot, Charles R. McClure, Carla B. Wright, Elise Jensen, and Susan Thomas, Public Libraries and the Internet 2007: Study Results and Findings (Tallahassee, Fla.: Information Institute, 2008). http:/ / www.ii.fsu.edu/projectFiles/plinternet/ 2007/2007_plinternet.pdf (accessed Sept. 10, 2008).

6. Charles R. McClure and Paul T. Jaeger, Public Libraries and Internet Service Roles: Measuring and Maximizing Internet Services (Chicago: ALA, 2008).

7. George D'Elia, June Abbas, Kay Bishop, Donald Jacobs, and Eleanor Jo Rodger, "The Impact of Youth's Use of the Internet on the Use of the Public Library," Journal of the American Society for Information Science \& Technology 58, no. 14 (2007): 2180-96; George D'Elia, Corinne Jorgensen, Joseph Woelfel, and Eleanor Jo Rodger, "The Impact of the Internet on Public Library Use: An Analysis of the Current Consumer Market for Library and Internet Services," Journal of the American Society for Information Science \& Technology 53, no. 10 (2002): 802-20.

8. National Center for Education Statistics (NCES), Public Libraries in the United States: Fiscal Year 2005 [NCES 2008301] (Washington, D.C.: National Center for Education Statistics, 2007); Pew American and Internet Life, "Internet Activities," http:// www.pewinternet.org/trends/Internet_Activities_2.15.08.htm (accessed Mar. 5, 2009).

9. Bertot et al., Public Libraries and the Internet 2007.

10. Ibid.

11. Cheryl Bryan, Managing Facilities for Results: Optimizing Space for Services (Chicago: Public Library Association, 2007); Joseph Matthews, Strategic Planning and Management for Library Managers (Westport, Conn.: Libraries Unlimited, 2005); Joseph Matthews, Technology Planning: Preparing and Updating a Library Technology Plan (Westport, Conn.: Libraries Unlimited, 2004); Diane Mayo and Jeanne Goodrich, Staffing For Results: A Guide to Working Smarter (Chicago: Public Library Association, 2002).

12. ALA, Libraries Connect Communities: Public Library Funding \& Technology Access Study (Chicago: ALA, 2008), http:// www.ala.org/ala/aboutala/offices/ors/plftas/0708report.cfm (accessed Mar. 5, 2008).

13. Charles P. Smith, ed., Motivation and Personality: Handbook of Thematic Content Analysis (New York: Cambridge Univ. 


\section{The MIT Press}

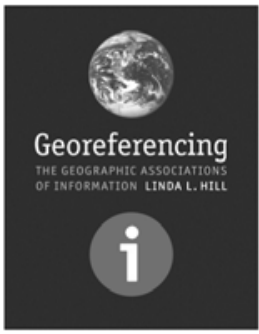

Now in Paper

\section{GEOREFERENCING}

The Geographic Associations of Information

Linda L. Hill

"The book provides a very useful primer for those beginning to design courses in the subject and is likely to become a classic in its field." - T. D. Wilson, Information Research

Digital Libraries and Electronic Publishing series 280 pp., 74 illus., $\$ 18$ paper

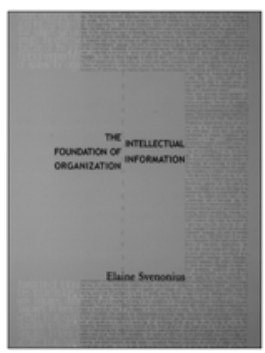

Now in Paper

\section{THE INTELLECTUAL}

FOUNDATION

OF INFORMATION

ORGANIZATION

\section{Elaine Svenonius}

"The Intellectual Foundations of Information Organization is a dense, intellectually rigorous, and well-written book... A major contribution to the field of cataloging." - Journal of the Association for History and Computing

Digital Libraries and Electronic Publishing series 280 pp. $\$ 24$ paper

To order call 800-405-1619 • http://mitpress.mit.edu
Pr., 1992); Klaus Krippendorf, Content Analysis: An Introduction to its Methodology (Beverly Hills, Calif.: Sage, 1980).

14. ALA, Libraries Connect Communities.

15. Bertot et al., Public Libraries and the Internet 2006; Bertot et al., Public Libraries and the Internet 2007.

16. Ibid.

17. NCES, Public Libraries in the United States.

18. Bertot et al., Public Libraries and the Internet 2007.
19. American Libraries, "Branch closings and budget cuts threaten libraries nationwide," Nov. 7, 2008, http:/ /www .ala.org/ala / alonline/currentnews / newsarchive / 2008/November2008/ branchesthreatened.cfm (accessed Nov. 17, 2008).

20. ALA, Libraries Connect Communities.

21. Bertot et al., Public Libraries and the Internet 2006.

22. Bertot et al., Public Libraries and the Internet 2007. 